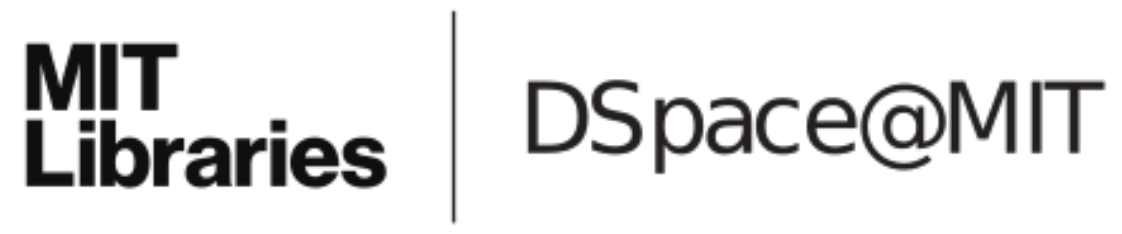

\author{
MIT Open Access Articles
}

Unpacking Skill Bias: Automation and New Tasks

The MIT Faculty has made this article openly available. Please share how this access benefits you. Your story matters.

Citation: Acemoglu, K. Daron and Pascual Restrepo. “Unpacking Skill Bias: Automation and New Tasks." American Economic Association Papers and Proceedings, 110 (May 2020): 356-361 (C) 2020 The Author(s)

As Published: 10.1257/PANDP.20201063

Publisher: American Economic Association

Persistent URL: https://hdl.handle.net/1721.1/130322

Version: Final published version: final published article, as it appeared in a journal, conference proceedings, or other formally published context

Terms of Use: Article is made available in accordance with the publisher's policy and may be subject to US copyright law. Please refer to the publisher's site for terms of use. 


\title{
Unpacking Skill Bias: Automation and New Tasks
}

\author{
By Daron Acemoglu and Pascual Restrepo*
}

Tinbergen's (1974) approach to inequality, based on the race between technological change increasing the demand for skills and the rise in the supply of skills due to education, has been a mainstay of labor economics. Its canonical formalization in the skill-biased technological change (SBTC) model of, inter alia, Katz and Murphy (1992) and Goldin and Katz (2008) has transformed the study of inequality and skills. In this model, technological change takes a factor-augmenting form and increases the productivity of skilled workers more than that of less skilled workers. In its most common version, changes in the demand for skills can be expressed as

$$
\text { (1) } d \ln \left(\frac{w_{H}}{w_{L}}\right)=-\frac{1}{\sigma} d \ln \left(\frac{H}{L}\right)+\frac{\sigma-1}{\sigma} d \ln \left(\frac{A_{H}}{A_{L}}\right) \text {, }
$$

where $w_{H} / w_{L}$ is the skill premium, $H / L$ is the relative supply of skills, $\sigma$ is the elasticity of substitution between skilled and unskilled workers, and $A_{L}$ and $A_{H}$ are factor-augmenting technologies for unskilled and skilled workers, respectively. In Katz and Murphy's seminal paper, $\sigma$ is estimated to be around 1.4, and, combined with a steady growth path for $A_{H} / A_{L}$, this model accounts for the time series of the college premium in the United States fairly successfully.

As argued in Acemoglu and Autor (2011), however, this framework is restrictive in some crucial respects. It does not help us understand the occupational trends in the labor market of most advanced economies, whereby, rather than general skill upgrading, we see the

\footnotetext{
*Acemoglu: Massachusetts Institute of Technology (email: daron@mit.edu); Restrepo: Boston University (email: pascual@bu.edu). We thank Chad Jones and participants in the Allied Social Sciences Association 2020 meeting for their comments, and Google, the National Science Foundation, Schmidt Sciences, the Smith Richardson Foundation, and the Sloan Foundation for financial support.

${ }^{\dagger}$ Go to https://doi.org/10.1257/pandp.20201063 to visit the article page for additional materials and author disclosure statement $(\mathrm{s})$.
}

disappearance of middle-skill occupations such as production and clerical jobs. More importantly, as pointed out in Acemoglu and Restrepo (2019), the economic mechanism in the canonical SBTC model is the substitution of the tasks and goods produced by skilled workers who are becoming more productive for those produced by less skilled workers (and is thus mediated by the elasticity of substitution $\sigma$ ). This implies that the canonical SBTC model cannot account for major changes in the US labor market without technological regress. First, without technological regress, real wages of unskilled workers should be rising, whereas in the United States over the past four decades, they have declined notably. Second, even if $A_{L}$ were constant, this model could generate the rise in the US college premium between 1963 and 1987 only with a growth of 11.3 percent per annum in $A_{H}$. But this would translate into at least a 1.9 percent increase in total factor productivity (TFP), whereas the US TFP over this time period grew by only 1.2 percent per annum (the same applies for the more recent 1992-2008 period; see the online Appendix).

Acemoglu and Autor (2011) and Acemoglu and Restrepo $(2018,2019)$ propose a task-based model that redresses some of these problems and extends the types of technological changes that affect the demand for skills (see also Autor, Levy, and Murnane 2003). At the center of the framework are (i) the allocation of tasks to different factors of production (skilled labor, unskilled labor, and capital) and (ii) new technologies that affect the productivity of factors in specific tasks and, as with automation, change the task content of production. In this framework, the effect of technology on the demand for skills and wages is not mediated via the elasticity of substitution, the impacts of technology on productivity and wages are decoupled, and new technologies can easily reduce wages for some workers. In this paper, we develop a flexible version of this conceptual framework, study the impact of different types of technologies on productivity and wages, and 
provide evidence on the link between automation and inequality. 1 ]

\section{A Model of Tasks, Output, and Inequality}

We start with a single-industry model. The unique final good is produced from a mass $M$ of tasks $x \in \mathcal{T}$ combined via a constant elasticity of substitution aggregator:

$$
Y=\left(\frac{1}{M} \int_{\mathcal{T}}(M y(x))^{\frac{\lambda-1}{\lambda}} d x\right)^{\frac{\lambda}{\lambda-1}}
$$

where $\lambda \geq 0$ is the elasticity of substitution between tasks. Tasks are performed by unskilled labor $\ell(x)$, skilled labor $h(x)$, or capital $k(x)$ :

$$
y(x)=\psi_{L}(x) \ell(x)+\psi_{H}(x) h(x)+\psi_{K}(x) k(x),
$$

where $\psi_{j}(x) \equiv A_{j} \cdot \gamma_{j}(x)$ for $j \in\{L, H, K\}$ denotes the productivity of factor $j$ at task $x$.

We assume $k(x)$ is produced using $q(x)$ units of the final good, while skilled and unskilled labor is supplied inelastically, with market-clearing conditions $L=\int_{\mathcal{T}} \ell(x) d x$ and $H=\int_{\mathcal{T}} h(x) d x$. We denote by $\mathcal{T}_{L}, \mathcal{T}_{H}$, and $\mathcal{T}_{K}$ the set of tasks performed by each factor. A competitive equilibrium is represented by an allocation of tasks to factors and production of capital goods that maximizes net output $Y-\int_{x} q(x) k(x) d x$. The online Appendix shows that net output is given by

$$
N Y=\left(\Gamma_{L}^{\frac{1}{\lambda}}\left(A_{L} L\right)^{\frac{\lambda-1}{\lambda}}+\Gamma_{H}^{\frac{1}{\lambda}}\left(A_{H} H\right)^{\frac{\lambda-1}{\lambda}}\right)^{\frac{\lambda-1}{\lambda}},
$$

where the share parameters, $\Gamma_{L}$ and $\Gamma_{H}$, are endogenously determined and represent the range of tasks performed by the two types of labor:

$$
\Gamma_{j}=\frac{\frac{1}{M} \int_{\mathcal{T}_{j}} \gamma_{j}(x)^{\lambda-1} d x}{1-\frac{1}{M} \int_{\mathcal{T}_{K}}\left(\frac{\psi_{K}(x)}{q(x)}\right)^{\lambda-1} d x} \text { for } j \in\{L, H\} .
$$

\footnotetext{
${ }^{1}$ Our companion paper, Acemoglu and Restrepo (2020), develops a multisector model with multiple skill types and estimates the contribution of factor-augmenting technological changes and changes in the task content of production to the evolution of US wage structure. It finds that the bulk of the changes are due to the task content of production.
}

Analogously to equation (1) in the canonical SBTC model, the effects of various technologies on the skill premium can be expressed as

$$
\text { (2) } \begin{aligned}
d \ln \left(\frac{w_{H}}{w_{L}}\right)= & -\frac{1}{\sigma} d \ln \left(\frac{H}{L}\right)+\frac{\sigma-1}{\sigma} d \ln \left(\frac{A_{H}}{A_{L}}\right) \\
& +\left.\frac{1}{\lambda} d \ln \left(\frac{\Gamma_{H}}{\Gamma_{L}}\right)\right|_{\frac{A_{H} H}{A_{L} L}},
\end{aligned}
$$

where the last term - the main difference from equation (1) - is evaluated at the initial ratio of effective skilled to unskilled labor, $A_{H} H / A_{L} L$, and captures the effect of changes in the allocation of tasks to factors on the skill premium. Moreover,

$$
\sigma=\lambda /\left(1-\frac{\partial \ln \left(\Gamma_{H} / \Gamma_{L}\right)}{\partial \ln \left(A_{H} H / A_{L} L\right)}\right) \geq \lambda
$$

is the derived elasticity of substitution between skilled and unskilled labor. This elasticity reflects two types of substitution: substitution between tasks, represented by $\lambda$ (with more productive skilled labor, there is greater production of skill-intensive tasks), and substitution at the extensive margin, whereby some tasks are reallocated from unskilled labor and capital to skilled labor. It is because of this second type of substitution that $\sigma \geq \lambda$.

In addition to factor-augmenting changesthe $A_{L}, A_{H}$, and $A_{K}$ terms - that increase the productivity of a factor in all tasks, this framework enables us to analyze the impact of technologies that affect the productivity of a factor in some tasks. Particularly relevant is automationchanges that enable capital to be used in tasks that were previously performed by labor (or equivalently increase the productivity of capital in such tasks). For example, robots can become more productive in welding, a task that was previously performed by human welders. The effects of automation and other technological changes affecting the allocation of tasks to factors work through the last term in equation (2).

Formally, consider an increase in $\gamma_{K}(x)$ for a set of tasks currently not in $\mathcal{T}_{K}$. This type of advance in automation technology will lead to an expansion in the set of tasks allocated to capital, $\mathcal{T}_{K}$. Automation can displace skilled or unskilled labor. In the context of industrial robotics technology, the evidence presented in Acemoglu and Restrepo (forthcoming) suggests that most of the automated tasks used to be 
performed by less skilled workers, and we start with this case. We also simplify the analysis by assuming that $\gamma_{K}(x)=0$ for all $x \notin \mathcal{T}_{K}$ and that if a task can be automated and produced by capital it will be produced by capital in equilibrium (see the online Appendix for primitive conditions that ensure this).

PROPOSITION 1: Consider an improvement in automation technologies such that the productivity of capital in a set of tasks in $\mathcal{A} \subset \mathcal{T}_{L}$ increases to $\psi_{K}(x)>0$. Then

$$
d \ln \left(\frac{w_{H}}{w_{L}}\right)=\frac{1}{\sigma} \frac{\int_{\mathcal{A}} \gamma_{L}(x)^{\lambda-1} d x}{\int_{\mathcal{T}_{L}} \gamma_{L}(x)^{\lambda-1} d x} .
$$

Moreover, $w_{H}$ increases, while $w_{L}$ may increase or decrease.

Several points are worth noting. First, the effect of automation technologies on the skill premium is completely driven by the set of tasks (weighted by their effective productivity) that unskilled labor loses relative to the entire set of tasks previously performed by these workers (and it is not mediated by the elasticity of substitution, and $\sigma$ does not need to be greater than one). This close connection between the set of tasks reallocated and factor price changes is the main conceptual insight of this class of models. Second, advances in automation technologies increase TFP, but these effects, coming from cost savings due to automation, may be small (see the online Appendix). Third, the magnitude of the change in the skill premium is decoupled from productivity increases. ${ }^{2}$ Fourth, the unskilled wage may decline, and this happens

\footnotetext{
${ }^{2}$ Specifically, in the canonical SBTC model, we have $\left.\frac{d \ln T F P}{d \ln \left(w_{H} / w_{H}\right)}\right|_{A_{L}}=s_{H} \cdot \sigma /(\sigma-1)$, where $s_{H}$ is the share of skilled labor in value added. Thus, to get the
}

demand for skilled labor to increase by 1 percent, one needs a 0.83 percent increase in productivity. Instead, in our model, in response to automation, $\frac{d \ln T F P}{d \ln \left(w_{H} / w_{L}\right)}=\sigma \cdot s_{L} \cdot \pi$, where $\pi>0$ is the average proportional cost reduction in automated tasks. This expression shows that, when $\pi \rightarrow 0$, our model generates large swings in the skill premium from very small changes in TFP. Because of this difference, our framework generates sizable changes in the skill premium for reasonable changes in TFP. For example, if automation reduces the cost of producing a task by $\pi=30$ percent, as in the case of industrial robots, then the increase in the college precisely when the increase in TFP is small (Acemoglu and Restrepo 2018), but the skilled wage always increases because tasks produced by other factors, which are $q$ complements to those produced by skilled workers, are becoming cheaper. ${ }^{3}$

This framework also allows us to study the implications of new labor-intensive tasks. The role of new tasks is emphasized in Acemoglu and Restrepo $(2018,2019)$ in both maintaining a stable labor share in GDP in the face of steady automation and as a source of productivity growth. For example, design tasks, most manufacturing engineering tasks, most back-office activities, and all programming occupations are new relative to the first half of the twentieth century and have been major drivers of the growth of labor demand.

PROPOSITION 2: Suppose a small set of new tasks (expanding $M$ ) is introduced. If skilled workers have comparative advantage in these tasks-that is, $w_{H} / \psi_{H}(x)<w_{L} / \psi_{L}(x)$ at current wages-then the skill premium increases by

$$
d \ln \left(\frac{w_{H}}{w_{L}}\right)=\frac{1}{\sigma} \frac{\int_{\mathcal{N}} \gamma_{H}(x)^{\lambda-1} d x}{\int_{\mathcal{T}_{H}} \gamma_{H}(x)^{\lambda-1} d x} .
$$

If, on the other hand, unskilled workers have comparative advantage in these tasks-that is, $w_{L} / \psi_{L}(x)<w_{H} / \psi_{H}(x)$ at current wagesthen the skill premium will decline by

$$
d \ln \left(\frac{w_{H}}{w_{L}}\right)=-\frac{1}{\sigma} \frac{\int_{\mathcal{N}} \gamma_{L}(x)^{\lambda-1} d x}{\int_{\mathcal{T}_{L}} \gamma_{L}(x)^{\lambda-1} d x} .
$$

The interpretation of this proposition is similar to that of Proposition 1. In particular, the effect on the skill premium is again a function of the set of tasks reallocated across factors. Analogously, these changes always increase TFP, but small changes in TFP can go hand in hand with sizable changes in the skill premium.

premium between 1963 and 1987 can be explained with as little as 0.54 percent per annum growth in TFP.

${ }^{3}$ Some of the automated tasks in $\mathcal{A}$ may have previously been performed by skilled workers: artificial intelligence may replace tasks currently employing skilled workers, and many of the iconic innovations of the industrial revolution automated spinning, weaving, and knitting tasks previously performed by skilled artisans. If so, automation may have the opposite effect on the skill premium. 
Also notable is that new tasks may increase or reduce the skill premium, depending on whether they are allocated to skilled or unskilled labor. ${ }^{4}$

Two other types of technological changes can be studied in this framework. The first is "standardization," which involves the simplification of previously complex and skilled tasks so that they can now be more cheaply performed by unskilled workers. The second is "skill upgrading," which involves the transformation of unskilled tasks so that they can be more productively performed by skilled workers. We derive the implications of these two types of technological changes in the online Appendix.

\section{Empirical Evidence from US Industries}

We next suppose that the model outlined in the previous section describes production at the industry level and then use industry-level data from the United States to investigate whether automation and new tasks are associated with changes in the relative demand for skills. We follow Acemoglu and Restrepo (2019), which shows how changes in the task content of production across industries can be estimated. We use data from the Bureau of Economic Analysis, the Bureau of Labor Statistics, and National Income and Product Accounts on factor shares, factor prices, and capital stocks for 1947-1987 and 1987-2016 at the three-digit industry level and exclude industries heavily dependent on commodity prices-in particular, oil and gas, mining, and agriculture, which exhibit large temporary fluctuations in factor shares. This leaves us with 44 industries. We combine these with data on wage bills and hours of work by college and high school workers from the US Censuses and the American Community Survey.

We follow Acemoglu and Restrepo (2019) in constructing estimates of displacement and reinstatement effects (corresponding to automation and the creation of new tasks) at the industry level for our two subperiods. Displacement

\footnotetext{
${ }^{4}$ This is in contrast to the extension considered in Acemoglu and Restrepo (2018), where we assume that new tasks are always performed by skilled workers.

${ }^{5}$ We follow Acemoglu and Autor (2011) and define college workers as those with a college degree and half of those with some college. High school workers are therefore those with a high school degree or less and half of those with some college.
}

(respectively, reinstatement) effects correspond to declines (respectively, increases) in the labor share of value added in an industry not explained by changes in factor prices over a five-year period. In the online Appendix, we provide details on data sources and the construction of these variables and present descriptive statistics. Both measures are expressed in percent changes, so that a 0.1 displacement corresponds to a 10 percent decline in the labor share.

Using these measures, we estimate the following model separately for the two periods:

$$
\begin{aligned}
\Delta \text { Skill Dem }_{i}= & \beta_{d} \text { displacement }_{i} \\
& +\beta_{r} \text { reinstatement }_{i}+\varepsilon_{i},
\end{aligned}
$$

where $\quad \Delta$ Skill Dem - our measure of industry-level increase in the relative demand for skills-is the change in the log of the college wage bill relative to the high school wage bill in each industry during the relevant period. All regressions are weighted by the average share of the wage bill accounted by the industry during the period. These regression results are presented in the online Appendix. Here we depict them visually.

Figure 1 shows a strong association between industry-level demand for skills and our measures of displacement (due to automation) and reinstatement (due to new tasks). During both subperiods, displacement is associated with increases in the relative demand for skills of the industry, though displacement changes are larger and the relationship becomes steeper in 1987-2016, as shown in panel B. A 10 percent increase in displacement during 1987-2016 is associated with an 8 percent increase in the relative demand for college workers (standard error $=0.015$ ). This estimate implies that displacement alone explains about 30 percent of the variation in the demand for skills across industries during this period. $\square^{\top}$ Panels $\mathrm{C}$ and D

\footnotetext{
${ }^{6}$ The 0.55 percent increase in displacement per annum at the aggregate level during this period could account for as much as a 0.44 percent increase in the demand for college skills (out of an estimated shift in the relative demand of 2.4 percent per annum (see Acemoglu and Autor 2011)). Assuming that $\pi=30$ percent, this substantial increase in the relative demand for college skills is consistent with automation technologies increasing TFP by as little as 0.11 percent per annum between 1987 and 2016.
} 
Panel A. Displacement, 1947-1987

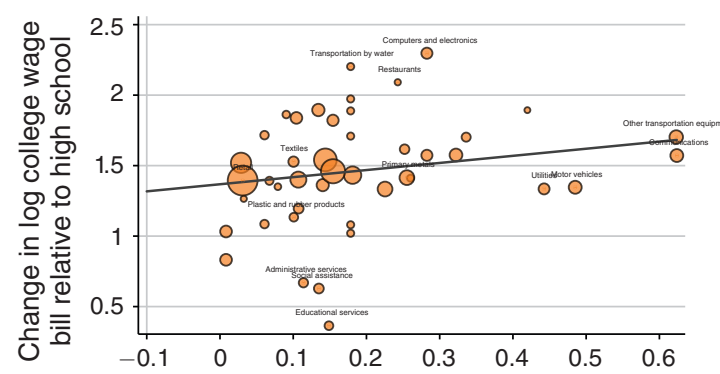

Panel C. Reinstatement 1947-1987

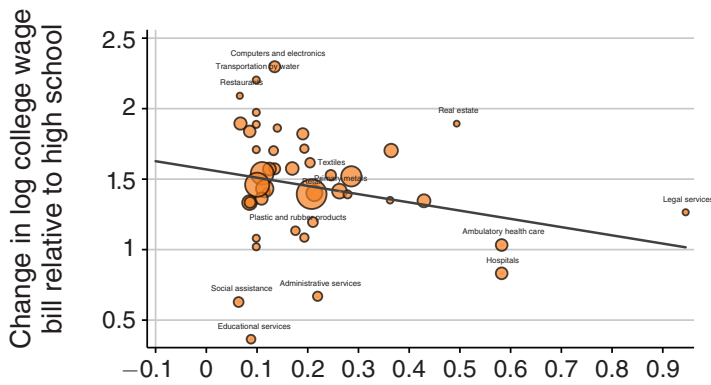

Panel B. Displacement, 1987-2016

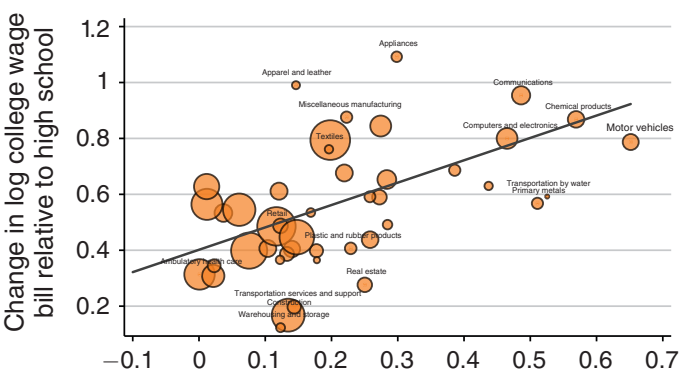

Panel D. Reinstatement 1987-2016

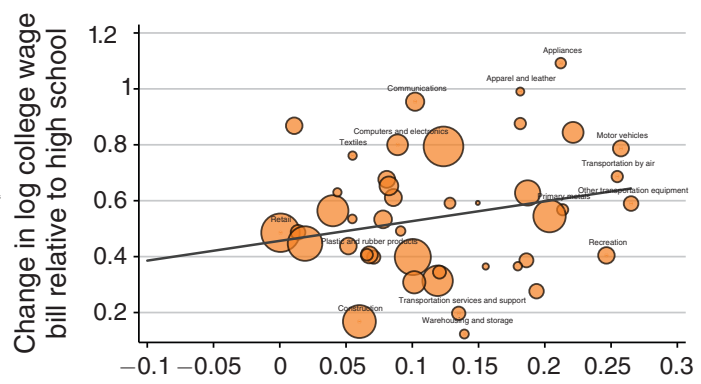

Figure 1. Change in Relative Demand for Skills 1947-1987 and 1987-2016 versus Displacement and Reinstatement

Notes: Relative demand for skills is measured as the log of the college wage bill relative to the high school wage bill. See the online Appendix for details and derivation of the estimates for displacement and reinstatement.

depict the relationship between reinstatement and the demand for skills. Greater reinstatement is associated with lower relative demand for skills during 1947-1987, presumably because unskilled labor had a comparative advantage in many of the new tasks introduced during this period. In contrast, reinstatement goes hand in hand with greater demand for skills in 19872016, which we interpret as new tasks being allocated to skilled workers during the past three decades. Our estimates suggest that during this latter period, a 10 percent increase in reinstatement is associated with a 7 percent increase in the relative demand for college workers (standard error $=0.035)$. $^{7}$

\footnotetext{
${ }^{7}$ The online Appendix provides several robustness checks, using different measures of the demand for skills and different constructions of the displacement and reinstatement effects, and also presents estimates from several regression models. These results confirm the patterns summarized in the text.
}

\section{Conclusion}

Automation and new tasks can have sizable effects on the demand for skills and factor prices (including declines in the wages for some or all types of labor), while leading to only small changes in TFP. These effects are not mediated by the elasticity of substitution between factors and instead operate via the changes in the allocation of factors to tasks (the task content of production). This contrasts with factor-augmenting technological changes, which are assumed to raise the productivity of factors in all tasks and therefore always cause large TFP increases.

We have argued that the canonical SBTC model can be significantly enriched by incorporating this task-level perspective and technologies that change the allocation of tasks to factors. We also document that proxies for automation and the introduction of new tasks are robustly associated with changes in the relative demand for skills at the industry level. This perspective further suggests that a primary 
reason for the increase in the skill premium (and the decline in the real wages of less skilled workers) has been rapid automation that has replaced tasks previously performed by less skilled workers.

\section{REFERENCES}

Acemoglu, Daron, and David Autor. 2011. "Skills, Tasks and Technologies: Implications for Employment and Earnings." In Handbook of Labor Economics, Vol. 4, Pt. B, edited by David Card and Orley Ashenfelter, 1043-71. Amsterdam: North Holland.

-Acemoglu, Daron, and Pascual Restrepo. 2018. "The Race between Man and Machine: Implications of Technology for Growth, Factor Shares, and Employment." American Economic Review 108 (6): 1488-542.

Acemoglu, Daron, and Pascual Restrepo. 2019. "Automation and New Tasks: How Technology Displaces and Reinstates Labor." Journal of Economic Perspectives 33 (2): 3-30.
Acemoglu, Daron, and Pascual Restrepo. 2020. "Automation and Inequality." Massachusetts Institute of Technology.

Acemoglu, Daron, and Pascual Restrepo. Forthcoming. "Robots and Jobs: Evidence from US Labor Markets." Journal of Political Economy.

Autor, David H., Frank Levy, and Richard J. Murnane. 2003. "The Skill Content of Recent Technological Change: An Empirical Exploration." Quarterly Journal of Economics 118 (4): 1279-333.

Goldin, Claudia, and Lawrence F. Katz. 2008. The Race between Education and Technology. Cambridge, MA: President and Fellows of Harvard College.

Katz, Lawrence F., and Kevin M. Murphy. 1992. "Changes in Relative Wages, 1963-1987: Supply and Demand Factors." Quarterly Journal of Economics 107 (1): 35-78.

Tinbergen, Jan. 1974. "Substitution of Graduate by Other Labor." Kyklos 27 (2): 217-26. 